\title{
Article
}

Mycosphere

Doi 10.5943/mycosphere/9/6/8

\section{Morphological and molecular identification of two novel species of Melanops in China}

\author{
Jiang $\mathrm{N}^{1}$, Phillips $\mathrm{AJL}^{2}$, Zhang $\mathrm{ZX}^{3}$ and Tian $\mathrm{CM}^{\mathbf{1}^{*}}$ \\ ${ }^{1}$ The Key Laboratory for Silviculture and Conservation of Ministry of Education, Beijing Forestry University, Beijing \\ 100083, China \\ ${ }^{2}$ Universidade de Lisboa, Faculdade de Ciências, Biosystems and Integrative Sciences Institute (BioISI), Campo \\ Grande, 1749-016 Lisbon, Portugal \\ ${ }^{3}$ Forest Diseases and Insect Pests Control Station of Tongliao City, Tongliao 028000, China
}

Jiang N, Phillips AJL, Zhang ZX, Tian CM 2018 - Morphological and molecular identification of two novel species of Melanops in China. Mycosphere 9(6), 1187-1196, Doi 10.5943/mycosphere/9/6/8

\begin{abstract}
Melanops is an uncommon genus in Botryosphaeriales that until now has been found only on Fagaceae hosts. It can be distinguished from the other Botryosphaeriales by having large, multiloculate ascomata and conidiomata with locules arranged at various levels within the stroma and a narrow, persistent mucous sheath surrounding the ascospores and conidia. In the present study, the morphology and phylogenetic relationships of Melanops specimens collected from Castanea mollissima and Quercus sp. in China were studied. As a result, Melanops castaneicola sp. nov. and Melanops chinensis sp. nov. are introduced, and a comparison with accepted Melanops species is presented.
\end{abstract}

Key words - Botryosphaeriales - Castanea - Melanopsaceae - Quercus - Taxonomy

\section{Introduction}

Melanops (Melanopsaceae, Botryosphaeriales) is a small genus comprising only M. tulasnei and an unnamed culture, CBS 118.39, possibly M. quercuum. Melanops is the sole genus representing Melanopsaceae (Crous et al. 2006, Phillips \& Alves 2009, Slippers et al. 2013, Wijayawardene et al. 2017). Morphologically, Melanopsaceae differs from the other genera in Botryosphaeriales on account of the relatively large, multiloculate ascomata and condiomata with locules arranged at various levels within the stroma, and ascospores and conidia surrounded by a narrow, persistent mucous sheath (Phillips \& Pennycook 2004, Phillips \& Alves 2009, Slippers et al. 2013). Melanopsaceae groups most basal in the Botryosphaeriales, together with Aplosporellaceae, Planistromellaceae and Saccharataceae (Phillips et al. 2013, 2018, Slippers et al. 2013, Wyka \& Broders 2016, Yang et al. 2017).

Botryosphaeriales are widespread, common and important fungal pathogens of woody plants, and many are also known to exist as endophytes in healthy plant tissues (Slippers et al. 2017). However, whether Melanops tulasnei is pathogenic or endophytic is not known, as it appears to infect woody tissue and sporulate on the dead tissue similar to other Botryosphaeriales.

In an ongoing study of Botryosphaeriales in China, specimens with typical characteristics of Melanops were collected from Fagaceae trees. The purpose of the work presented here was to identify the fungi in terms of morphology and phylogeny. 


\section{Materials \& Methods}

\section{Isolates and morphology}

Two fresh specimens from dead and dying Castanea mollissima and two from Quercus sp. trees were collected from Hebei and Shaanxi Provinces in China. Single conidial isolates were established by spreading a mucoid spore mass taken from conidiomata onto the surface of PDA plates. After $48 \mathrm{~h}$ of incubation at $25^{\circ} \mathrm{C}$, plates were examined with a dissecting microscope and single germinating spores were transferred with a sterile needle to fresh plates of PDA. Herbarium specimens were deposited in the Museum of Beijing Forestry University (BJFC) and cultures maintained in the China Forestry Culture Collection Center (CFCC).

Species were identified based on morphological features of the conidiomata and conidia produced on the dead and dying plant tissues. Cross-sections of conidiomata were cut by hand with a razor blade. Specimens for microscopy were mounted in $100 \%$ lactic acid. At least 20 conidiomata and 50 conidia were measured to calculate their mean size and standard deviation. Dimensions are reported as maximum and minimum in parentheses and the range representing the mean, plus or minus the standard deviation with the number of measurements given in parentheses (Voglmayr et al. 2017). Microscope images were captured with a Nikon Eclipse 80i microscope equipped with a Nikon digital sight DS-Ri2 high definition colour camera, using differential interference contrast (DIC) illumination and the Nikon software NIS-Elements D Package v. 3.00. Culture characteristics of isolates were recorded after one month of incubation on PDA in the dark at $25^{\circ} \mathrm{C}$.

\section{Molecular characterization and multi-locus phylogenetic analysis}

Genomic DNA was extracted from cultures grown on PDA overlaid with cellophane using a modified CTAB method (Doyle \& Doyle 1990). The internal transcribed spacer (ITS), ribosomal large subunit (LSU), part of the translation elongation factor $1 \alpha$ (tefl) and part of the beta-tubulin (tub2) gene, were amplified with the primers ITS1 and ITS4 (White et al. 1990), LR0R and LR5 (Moncalvo et al. 1995, Vilgalys \& Hester 1990), EF1-688F and EF1-986R (Alves et al. 2008, Carbone \& Kohn 1999), and Bt2a and Bt2b (Glass \& Donaldson 1995), respectively. PCR was done by the methods described by Phillips \& Alves (2009). The PCR amplification products were visualised by electrophoresis in $2 \%$ agarose gels and sequenced by Shanghai Invitrogen Biological Technology Company Limited (Beijing, China).

Sequences obtained from this study and reference sequences obtained from GenBank (Table 1) were aligned and edited manually using MEGA6 (Tamura et al. 2013). The alignments were concatenated for phylogenetic analyses. Maximum parsimony (MP) analysis was conducted with PAUP v.4.0b10 (Swofford 2003), and maximum likelihood (ML) analysis with PhyML v.7.2.8 (Guindon et al. 2010). Sequences of novel species were deposited in GenBank (Table 1). The multilocus file was deposited in TreeBASE (www.treebase.org) as accession S23609. Introduction of the new species based on molecular data followed the recommendations of Jeewon \& Hyde (2016).

Table 1 Isolates used in the phylogenetic analysis, new strains from the current study are in red and ex-type strains in bold face.

\begin{tabular}{llllll}
\hline Species & Isolate no. $^{\text {a }}$ & ITS & LSU & tef1 $^{\text {tub2 }}$ \\
\hline Aplosporella javeedii & CMW 38166 & KC769939 & KC769980 & KC769847 & KC769908 \\
Aplosporella prunicola & CBS 121167 & KF766147 & JX681071 & N/A & N/A \\
Aplosporella yalgorensis & MUCC 511 & EF591927 & EF591944 & EF591978 & EF591961 \\
Bagnisiella examinans & CBS 551.66 & KF766148 & KF766316 & GU349056 & KF766126 \\
Barriopsis fusca & CBS 174.26 & KF766149 & DQ377857 & KF766395 & EU673109 \\
Botryosphaeria dothidea & CBS 115476 & KF766151 & KF766319 & AY236898 & AY236927 \\
\hline
\end{tabular}


Table 1 Continued.

\begin{tabular}{|c|c|c|c|c|c|}
\hline Species & Isolate no. $^{a}$ & ITS & LSU & tef1 & tub2 \\
\hline Cophinforma atrovirens & $\begin{array}{l}\text { MFLUCC } \\
110425\end{array}$ & JX646800 & JX646817 & JX646865 & JX646848 \\
\hline Diplodia rosulata & CBS 116470 & EU430265 & DQ377896 & EU430267 & EU673132 \\
\hline Dothiorella longicollis & CBS 122068 & KF766162 & KF766328 & EU144069 & KF766130 \\
\hline Dothiorella viticola & CBS 117009 & AY905554 & DQ377873 & AY905559 & EU673104 \\
\hline $\begin{array}{l}\text { Endomelanconiopsis } \\
\text { endophytica }\end{array}$ & CBS 120397 & EU683656 & EU683629 & EU683637 & KF766131 \\
\hline Guignardia bidwellii & CBS 111645 & FJ824766 & DQ377876 & EU683653 & FJ824777 \\
\hline Guignardia citricarpa & CBS 102374 & FJ824767 & DQ377877 & FJ538376 & FJ824778 \\
\hline Kellermania crassispora & CBS 131714 & KF766175 & KF766345 & KF766406 & KF766135 \\
\hline Kellermania dasylirionis & CBS 131715 & KF766177 & KF766347 & KF766408 & KF766137 \\
\hline Kellermania macrospora & CBS 131716 & KF766178 & KF766348 & KF766409 & KF766138 \\
\hline Kellermania nolinae & CBS 131717 & KF766180 & KF766350 & KF766411 & KF766140 \\
\hline Kellermania plurilocularis & CBS 131719 & KF766181 & KF766351 & KF766412 & KF766141 \\
\hline Kellermania yuccifoliorum & $\mathrm{CBS}$ & KF7 & KF766355 & KF766416 & KF76 \\
\hline Lasiodiplodia theobromae & CBS 164.96 & AY640255 & EU673253 & AY640258 & EU673110 \\
\hline Lecanosticta acicola & LNPV 252 & JX901755 & JX901844 & JX901639 & JX902213 \\
\hline Macrophomina phaseolina & & & DQ37' & KF95 & 1806 \\
\hline Marasasiomyces karoo & $\mathrm{CBS}$ & KF531828 & DQ377939 & KF531807 & KF531808 \\
\hline Melanops castaneicola & CFC & MK203065 & MK203069 & MK204619 & MK2 \\
\hline Melanops castaneicola & $\mathrm{CFCC}$ & MK203066 & MK203070 & MK204620 & MK2 \\
\hline Melanops chinensis & CFC & MK203067 & MK203071 & MK204621 & MK2 \\
\hline Melanops chinensis & CFCC 52983 & MK203068 & MK203072 & MK204622 & MK2 \\
\hline Melanops sp. & CBS 1 & FJ824771 & DQ377856 & FJ824776 & FJ82 \\
\hline Melanops tulasnei & CBS 116805 & FJ82 & FJ824764 & FJ824774 & FJ82 \\
\hline Melanops tulasnei & CBS 116806 & FJ824770 & FJ824765 & FJ824775 & FJ824781 \\
\hline Neodeightonia phoenicum & CBS 169.34 & EU6 & EU673 & EU67 & EU67 \\
\hline Neofusicoccum umdonicola & CMW 14 & EU8 & KF766373 & EU821874 & EU821844 \\
\hline Neoscytalidium dimidiatum & CBS 499.66 & AY819727 & DQ377925 & EU144063 & FM211167 \\
\hline Phaeobotryon mamane & СРC 12264 & EU673331 & DQ377898 & EU673297 & EU673125 \\
\hline Phaeobotryosphaeria citrigena & ICMP 16818 & EU673329 & EU673247 & EU673295 & EU673141 \\
\hline Phyllosticta minima & CBS 111635 & KF766215 & EU754194 & KF766433 & N/A \\
\hline Phyllosticta philoprina & CBS 616.72 & KF766171 & KF766341 & KF766402 & N/A \\
\hline Phyllosticta podocarpi & CBS 111647 & KF766217 & KF766383 & KF766434 & N/A \\
\hline Pseudofusicoccum stromaticum & CBS 117448 & KF766223 & DQ377931 & N/A & EU673094 \\
\hline Saccharata capensis & CBS 122693 & KF766224 & KF766390 & EU552095 & N/A \\
\hline Saccharata kirstenboschensis & CBS 123537 & KF766225 & FJ372409 & N/A & N/A \\
\hline Saccharata proteae & CBS 115206 & KF766226 & DQ377882 & KF766438 & KF531790 \\
\hline Septorioides pini-thunbergii & CBS 473.91 & KF251243 & KF251746 & N/A & KF252727 \\
\hline Sphaeropsis visci & CMW 39386 & KF575004 & KF575065 & KF575036 & KF575100 \\
\hline Septorioides strobi & CBS 141443 & KT884699 & KT884685 & KT884713 & KT884721 \\
\hline Septorioides strobi & SW14-36 & KT884692 & KT884678 & KT884706 & KT884720 \\
\hline
\end{tabular}

${ }^{\mathrm{a} A c r o n y m s ~ o f ~ c u l t u r e ~ c o l l e c t i o n s: ~ C M W: ~ T r e e ~ P a t h o l o g y ~ C o-o p e r a t i v e ~ P r o g r a m, ~ F o r e s t r y ~ a n d ~ A g r i c u l t u r a l ~}$ Biotechnology Institute, University of Pretoria, South Africa; CBS: CBS-KNAW Fungal Biodiversity Centre, Utrecht, The Netherlands; MUCC: Culture Collection, Laboratory of Plant Pathology, Mie University, Tsu, Mie pre-fecture, Japan; MFLUCC: Mae Fah Luang University Culture Collection, 
Chiang Mai, Thailand; LNPV: Laboratoire National de la Protection des Vegetaux Mycologie, Malzeville, France; ICMP: International Collection of Microorganisms from Plants, Plant Diseases Division, DSIR, Auckland, New Zealand.

\section{Results}

\section{Phylogenetic analyses}

The combined LSU, ITS, tef1 and tub2 data set consisted of 46 strains with Lecanosticta acicola (CBS 164.96) as the out group taxon (Wyka et al. 2016). The alignment comprised 2459 characters of which 1245 characters were constant and 352 variable characters were parsimonyuninformative. MP analysis of the remaining 862 parsimony-informative characters resulted in 2 equally most parsimonious trees, and the first tree $(\mathrm{TL}=4715, \mathrm{CI}=0.469, \mathrm{RI}=0.669, \mathrm{RC}=0.314)$ is shown in Fig. 1. The topology of the phylogenetic tree obtained from ML was similar to the MP tree. The two novel species appeared in two distinct clades with high bootstrap support (Fig. 1).

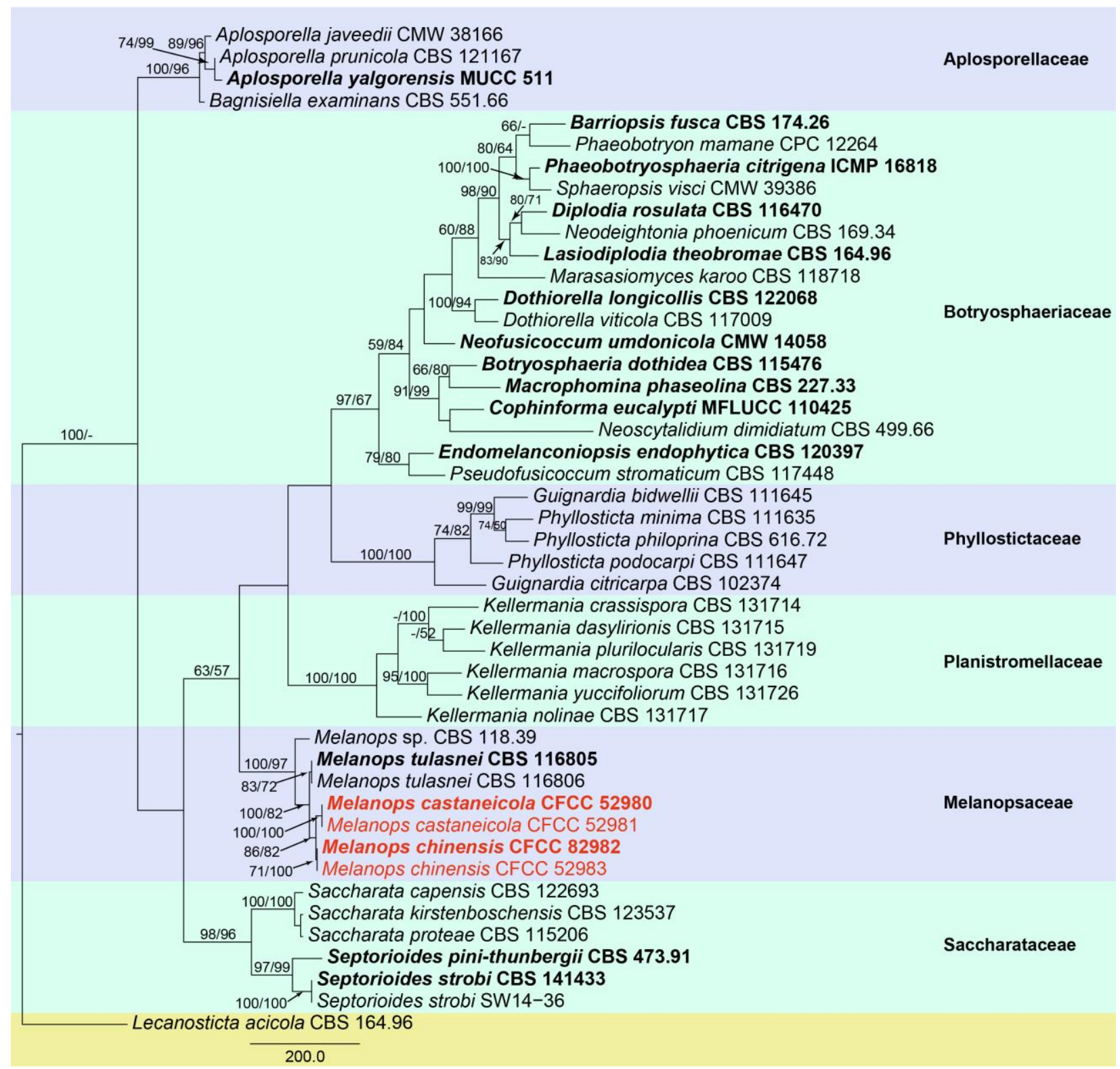

Figure 1 - Maximum parsimony tree of Botryosphaeriales based on combined LSU, ITS, tefl and tub2 sequences. MP/ML bootstrap support values greater than $50 \%$ are shown at the nodes. Scale bar $=200$ nucleotide substitutions. The two new species are highlighted in red. The ex-strains are in bold face. 
Melanops castaneicola C.M. Tian, A.J.L. Phillips \& N. Jiang, sp. nov.

Fig. 2

MycoBank number: MB 828676; Facesoffungi number: FoF05399

Etymology - Named after the host genus (Castanea) from which it was first isolated.

Typification - CHINA, Shaanxi Province, Ankang City, chestnut plantation, 3339'27.29"N, $109^{\circ} 07^{\prime} 15.24^{\prime \prime} \mathrm{E}, 2504 \mathrm{~m}$ asl, on dead and dying branches of Castanea mollissima, collected by N. Jiang, 8 July 2017 (BJFC-S1578, holotype), culture ex-holotype CFCC 52980.
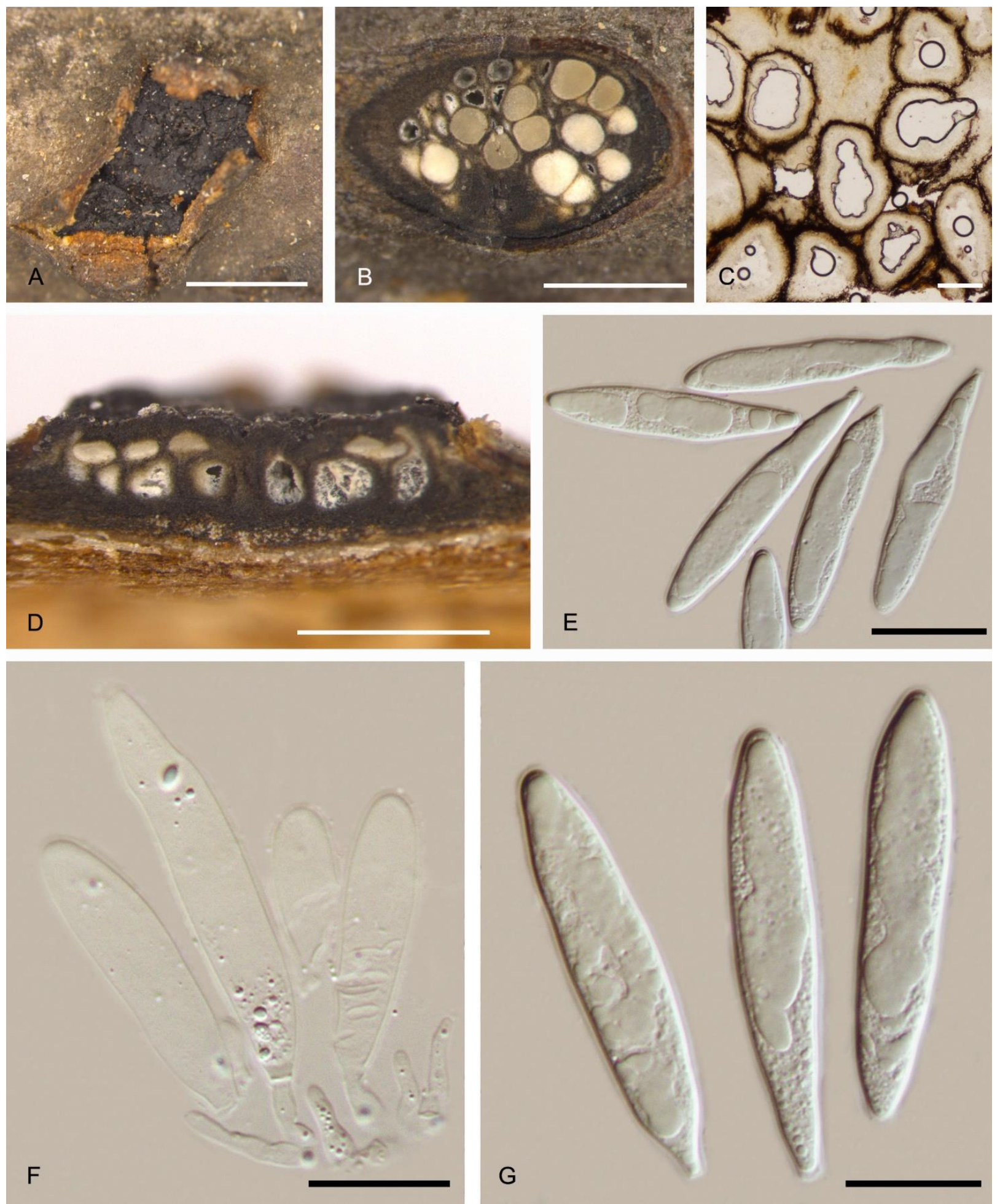

Figure 2 - Melanops castaneicola from Castanea mollissima (BJFC-S1578, holotype). A Habit of conidiomata erumpent through the bark. B, C Transverse sections through a conidioma. D Longitudinal section through a conidioma. E, G Conidia. F Conidiogenous cells. Scale bars: A, $\mathrm{B}, \mathrm{D}=0.5 \mathrm{~mm} ; \mathrm{C}=50 \mu \mathrm{m} ; \mathrm{E}=30 \mu \mathrm{m} ; \mathrm{F}, \mathrm{G}=20 \mu \mathrm{m}$. 
Sexual morph - Not observed. Asexual morph - Conidiomata 1-2 mm wide, 0.2-0.5 mm high, pycnidial, multilocular, thick-walled, dark brown to black, semi-immersed in the host becoming erumpent when mature. Wall composed of dark-walled, thick-walled cells of textura angularis becoming progressively thinner-walled and paler towards the loculi, individual locules 50-200 $\mu \mathrm{m}$ diameter. Ostioles circular and central on each locule, non-papillate. Paraphyses 1.5-2 $\mu \mathrm{m}$ wide, up to $30 \mu \mathrm{m}$ long, filiform, septate, unbranched, arising between the conidiogenous cells, tip rounded or slightly swollen. Conidiogenous cells, 5-15 $\times 2-4 \mu \mathrm{m}$, cylindrical, hyaline, unbranched, discrete, formed from the inner wall of the forming a single conidium at the tip and proliferating percurrently to form one or two annellations, rarely proliferating at the same level giving rise to periclinal thickenings. Conidia (50.2-)56.3-66.7(-72.1) $\times(12.4-) 12.9-14.6(-15.6)$ $\mu \mathrm{m}, 1 / \mathrm{w}=(3.5-) 4-5(-5.6)(\mathrm{n}=50)$, hyaline, aseptate, fusiform, widest in the middle, apex acute, base truncate with a minute marginal frill, surrounded by a narrow, persistent mucous sheath, contents granular.

Culture characters - On PDA at $25{ }^{\circ} \mathrm{C}$, cultures initially white, becoming grey after 1 week. Colonies flat, with irregular margins; texture initially uniform, producing concentric circles within 1 month at $25{ }^{\circ} \mathrm{C}$ in the dark.

Habitat and host range - on dead and dying branches of Castanea mollissima.

Additional specimen examined - CHINA, Shaanxi Province, Ankang City, chestnut plantation, $32^{\circ} 13^{\prime} 43.51^{\prime \prime} \mathrm{N}, 109^{\circ} 00^{\prime} 44.24^{\prime \prime} \mathrm{E}, 1810 \mathrm{~m}$ asl, on dead and dying branches of Castanea mollissima, collected by N. Jiang, 3 July 2017 (BJFC-S1579, paratype), living culture CFCC 52981.

Notes - Two isolates of Melanops castaneicola cluster in a well-supported clade (MP/ML = 100/100) sister to M. chinensis (Fig. 1). Melanops castaneicola can be distinguished from $M$. chinensis by its shorter conidia (56.3-66.7 $\mu \mathrm{m}$ in $M$. castaneicola vs. 68.1-73.7 $\mu \mathrm{m}$ in $M$. chinensis). Additionally, these two species inhabit different host genera (M. castaneicola on Castanea vs. M. chinensis on Quercus) in Fagaceae. Melanops castaneicola is separated from M. tulasnei by $10 \mathrm{bp}$ differences in ITS and 7 bp differences in tefl, while 5 bp differences in ITS and 4 bp differences in tefl separate it from $M$. chinensis.

Melanops chinensis C.M. Tian, A.J.L. Phillips \& N. Jiang, sp. nov.

Fig. 3

MycoBank number: MB828684; Facesoffungi number: FoF05398

Etymology - Named after the country where it was first found, China.

Typification - CHINA, Hebei Province, Qinhuangdao City, Zu Mountain, 40¹4'13.22"N, $119^{\circ} 43^{\prime 2} 28.42^{\prime \prime E}, 1125 \mathrm{~m}$ asl, on dead and dying branches of Quercus sp., collected by N. Jiang, 5 April 2018 (BJFC-S1580, holotype), culture ex-holotype CFCC 52982.

Sexual morph - Not observed. Asexual morph - Conidiomata 2-4 mm wide, 1-2.5 mm high, pycnidial, multilocular, thick-walled, dark brown to black, immersed in the host. Wall composed of dark-walled, thick-walled cells of textura angularis becoming progressively thinner-walled and paler towards the loculi, individual locules $150-450 \mu \mathrm{m}$ diameter. Ostioles circular and central on each locule, non-papillate. Paraphyses 1.5-2.5 $\mu \mathrm{m}$ wide, up to $25 \mu \mathrm{m}$ long, filiform, septate, unbranched, arising between the conidiogenous cells, tip rounded or slightly swollen. Conidiogenous cells 5-20 × 1.5-3.5 $\mu \mathrm{m}$, cylindrical, hyaline, unbranched, discrete, formed from the inner wall of the conidioma, forming a single conidium at the tip and proliferating percurrently to form one or two annellations, rarely proliferating at the same level giving rise to periclinal thickenings. Conidia (64.4-)68.1-73.7(-75.1) $\times(11.7-) 12.4-14.5(-15.6) \mu \mathrm{m}, 1 / \mathrm{w}=(4.4-) 4.7-$ $5.9(-6.4)(\mathrm{n}=50)$, hyaline, aseptate, fusiform, widest in the middle, apex acute, base truncate with a minute marginal frill, surrounded by a narrow, persistent mucous sheath, contents granular.

Culture characters - On PDA at $25^{\circ} \mathrm{C}$, cultures initially white, becoming grey to black after 1 week. Colonies are flat, with irregular margins; texture initially uniform, producing concentric circles within 1 month at $25{ }^{\circ} \mathrm{C}$ in the dark (Fig. 4).

Habitat and host range - on dead and dying branches of Quercus sp.

Additional specimen examined - CHINA, Qinhuangdao City, Zu Mountain, 40¹4'13.15"N, 
$119^{\circ} 43^{\prime 28.34 " E, ~} 1125 \mathrm{~m}$ asl, on dead and dying branches of Quercus sp., collected by N. Jiang, 5 April 2018 (BJFC-S1581, paratype), living culture CFCC 52983.
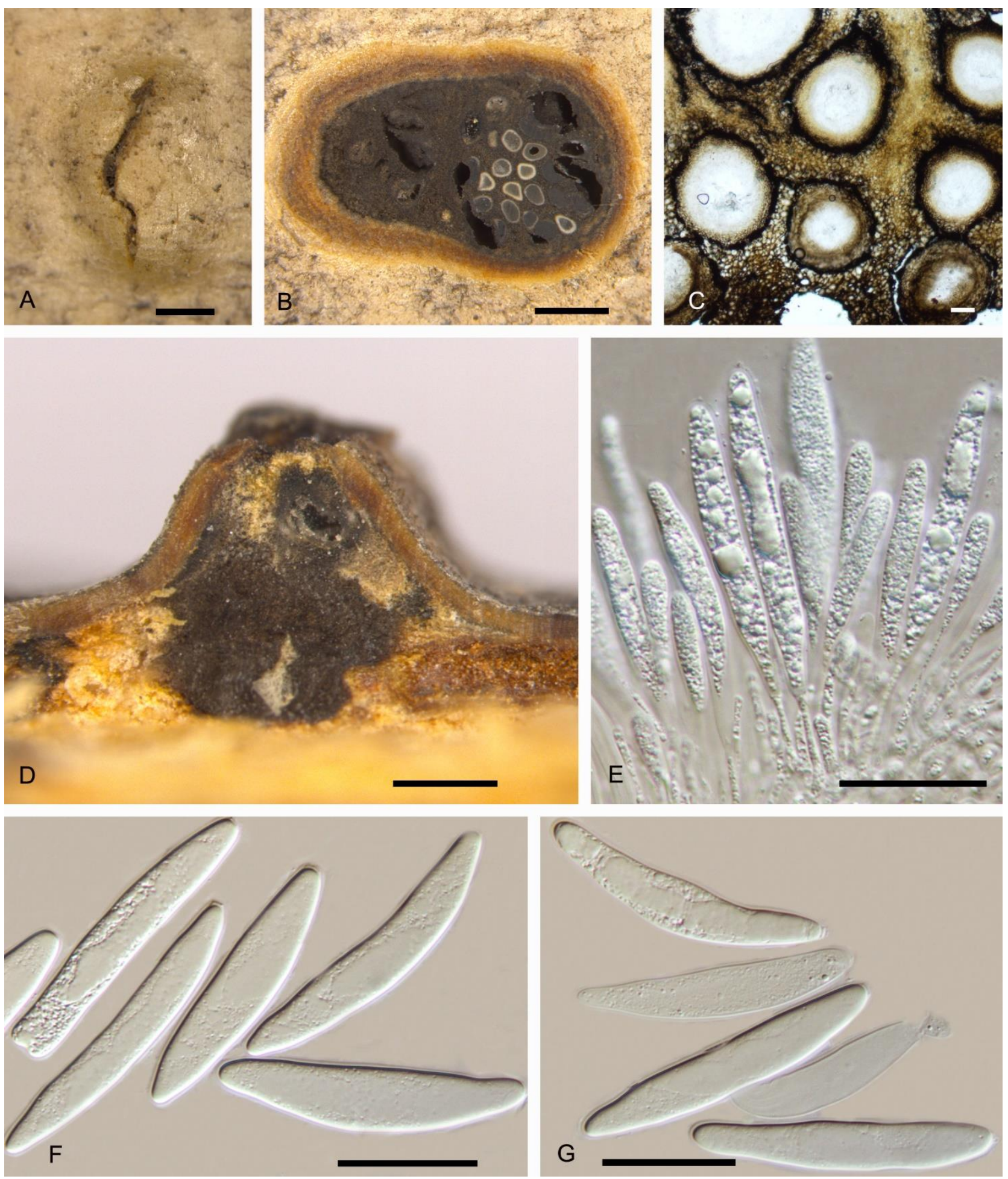

Figure 3 - Melanops chinensis from Quercus sp. (BJFC-S1580, holotype). A Habit of conidiomata immersed in the bark. B, C Transverse sections through conidiomata. D Longitudinal section through a conidioma. E Conidiogenous cells Conidia. F, G Conidia. Scale bars: A, B, D = $0.5 \mathrm{~mm}$, $\mathrm{C}=50 \mu \mathrm{m}, \mathrm{E}, \mathrm{G}=30 \mu \mathrm{m}$.

Notes - The two isolates of Melanops chinensis cluster in a well-supported clade (MP/ML = 71/100) (Fig. 1). Although Melanops chinensis was found on the same tree genus as M. tulasnei (Quercus), M. chinensis has larger conidia than M. tulasnei $(68.1-73.7 \times 12.4-14.5 \mu \mathrm{m}$ in $M$. 
chinensis vs. $45-46.8 \times 9.1-9.7 \mu \mathrm{m}$ in $M$. tulasnei) (Phillips \& Alves 2009). Furthermore, the two species are separated by 5 bp differences in ITS and 3 bp differences in tefl.

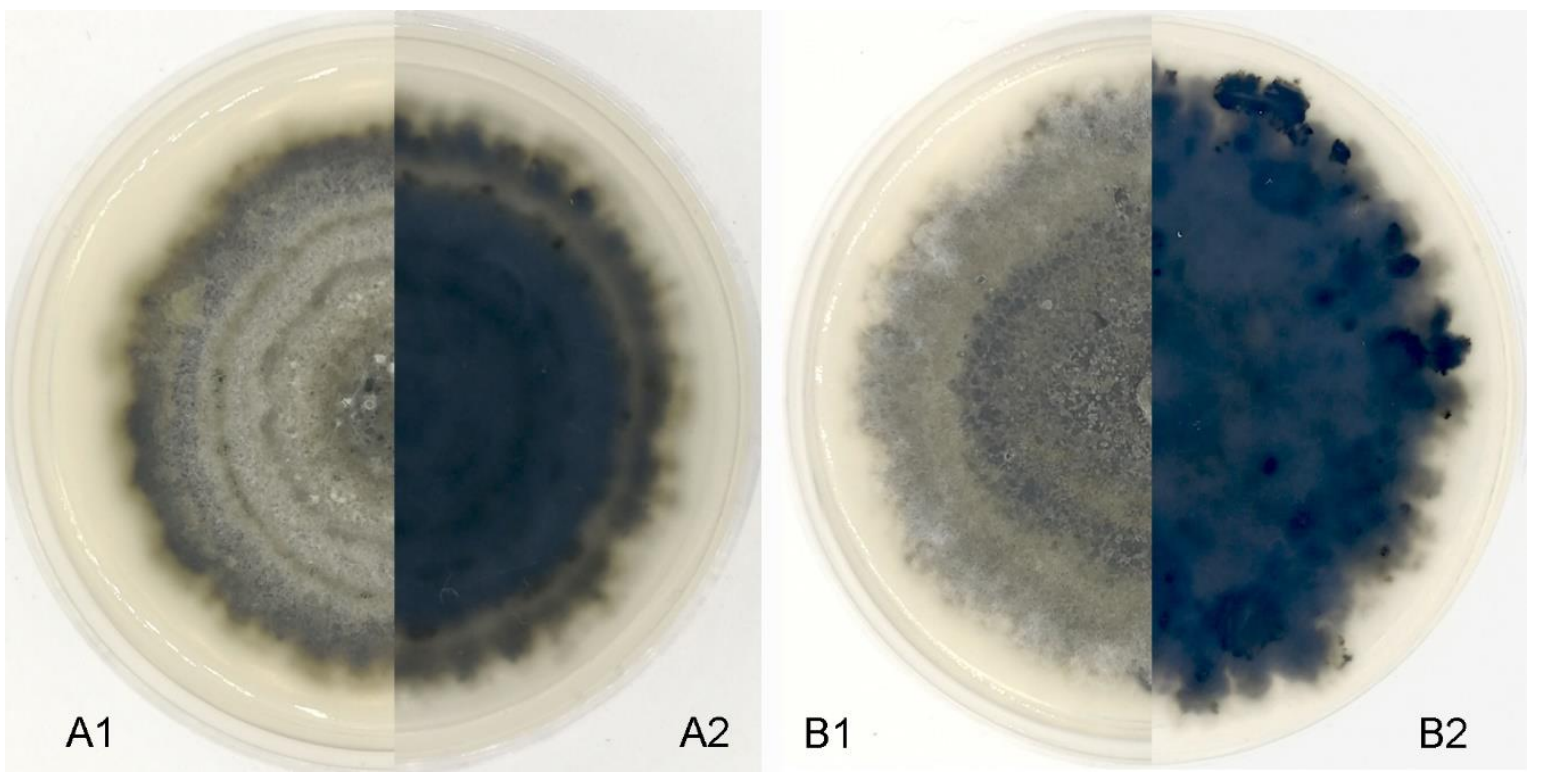

Figure 4 - Cultures on PDA after 1 month at $25{ }^{\circ} \mathrm{C}$. A1-A2 M. castaneicola. B1-B2 M. chinensis. $\mathrm{A} 1$ and $\mathrm{B} 1$ surface view, $\mathrm{A} 2$ and $\mathrm{B} 2$ reverse side of colonies.

\section{Discussion}

In this study, Melanops castaneicola and M. chinensis are introduced based on morphological and phylogenetic evidence. Hence, at least three Melanops species are now known from cultures and can be distinguished by differences in asexual fruiting bodies and conidial dimension (Table 2). Interestingly, all three species inhabit Fagaceae hosts in the northern hemisphere.

Table 2. Morphological comparison of three Melanops species.

\begin{tabular}{llll}
\hline Species & Melanops tulasnei & Melanops castaneicola & Melanops chinensis \\
\hline Conidial length $(\mu \mathrm{m})$ & $(37.2-) 45-46.8(-53)$ & $(50.2-) 56.3-66.7(-72.1)$ & $(64.4-) 68.1-73.7(-75.1)$ \\
Conidial width $(\mu \mathrm{m})$ & $(7.2-) 9.1-9.7(-12.1)$ & $(12.4-) 12.9-14.6(-15.6)$ & $(11.7-) 12.4-14.5(-15.6)$ \\
Length/width ratio & N/A & $(3.5-) 4-5(-5.6)$ & $(4.4-) 4.7-5.9(-6.4)$ \\
Distribution & USA, Canada, Germany, Italy & China & China \\
Host & Quercus sp. & Castanea mollissima & Quercus $\mathrm{sp}$. \\
Conidiomata & Semi-immersed & Semi-immersed & Immersed \\
\hline
\end{tabular}

Melanops chinensis forms asexual fruiting bodies fully immersed in the oak bark, different from $M$. castaneicola and M. tulasnei. It is reasonable that the formation of semi-immersed or fully immersed conidiomata is not related to the host, as Melanops tulasnei has semi-immersed conidiomata in oak barks (Phillips \& Alves 2009). The most obvious feature to distinct the three species is the conidial dimension (Table 2).

Currently 103 Melanops species names have been recorded in Index Fungorum (http://www.indexfungorum.org, 2018) and 109 records are in MycoBank (http://www.mycobank.org, 2018). However, some have been transferred to other families (mostly in Botryosphaeriales), the rest remain unsolved. As in the previous research, Phillips \& Alves could not establish any cultures of them (2009). Hence, more intensive sampling should be conducted to determine their correct taxonomic and phylogenetic position, which will reveal more unknown taxa.

Until now, whether Melanops species are pathogenic to their hosts or not is not known because they are not commonly found and seldom collected. Many Botryosphaeriales taxa have 
been proven to be phytopathogens on different plant parts (Phillips \& Alves 2009, Slippers et al. 2013, 2017), and Melanops species were collected from cankers on dead and dying branches in this study. Hence, Melanops species might contribute to canker diseases when hosts are stressed. Further collections and inoculation experiments are required, however, to confirm pathogenicity.

\section{Acknowledgements}

This study was financed by the National Natural Science Foundation of China (Project No.: 31670647). We thank Chungen Piao and Minwei Guo [China Forestry Culture Collection Center (CFCC), Chinese Academy of Forestry, Beijing], and Yingmei Liang [Museum of Beijing Forestry University (BJFC), Beijing Forestry University] for the preservation of materials collected during this study. Alan JL Phillips acknowledges the support from Biosystems and Integrative Sciences Institute (BioISI, FCT/UID/ Multi/04046/2013).

\section{References}

Alves A, Crous PW, Correia A, Phillips AJL. 2008 - Morphological and molecular data reveal cryptic speciation in Lasiodiplodia theobromae. Fungal Diversity 28, 1-13.

Carbone I, Kohn LM. 1999 - A method for designing primer sets for speciation studies in filamentous ascomycetes. Mycologia 91(3), 553-556.

Doyle JJ, Doyle JL. 1990 - Isolation of plant DNA from fresh tissue. Focus 12, 13-15.

Crous PW, Slippers B, Wingfield MJ, Rheeder J et al. 2006 - Phylogenetic lineages in the Botryosphaeriaceae. Studies in Mycology 55, 235-253.

Glass NL, Donaldson GC. 1995 - Development of primer sets designed for use with the PCR to amplify conserved genes from filamentous ascomycetes. Applied and Environmental Microbiology 61(4), 1323-1330.

Guindon S, Dufayard JF, Lefort V, Anisimova M et al. 2010 - New algorithms and methods to estimate maximum-likelihood phylogenies: assessing the performance of PhyML 3.0. Systematic and biology 59(3), 307-321.

Jeewon R, Hyde KD. 2016 - Establishing species boundaries and new taxa among fungi: recommendations to resolve taxonomic ambiguities. Mycosphere 7(11), 1669-1677.

Moncalvo JM, Wang HH, Hseu RS. 1995 - Phylogenetic relationships in Ganoderma inferred from the internal transcribed spacers and 25S ribosomal DNA sequences. Mycologia 87, 223-238.

Phillips AJL, Alves A. 2009 - Taxonomy, phylogeny, and epitypification of Melanops tulasnei, the type species of Melanops. Fungal Diversity 38, 155-166.

Phillips AJL, Alves A, Abdollahzadeh J, Slippers B et al. 2013 - The Botryosphaeriaceae: genera and species known from culture. Studies in Mycology 76, 51-167.

Phillips AJL, Hyde KD, Alves A, Liu JK. 2018 - Families in Botryosphaeriales: a phylogenetic, morphological and evolutionary perspective. Fungal Diversity (In Press).

Phillips AJL, Pennycook SR. 2004 - Taxonomy of Botryosphaeria melanops and its anamorph, Fusicoccum advenum. Sydowia 56(2), 288-295.

Slippers B, Boissin E, Phillips AJL, Groenewald JZ et al. 2013 - Phylogenetic lineages in the Botryosphaeriales: a systematic and evolutionary framework. Studies in Mycology 76, 31-49.

Slippers B, Crous PW, Jami F, Groenewald JZ, Wingfield MJ. 2017 - Diversity in the Botryosphaeriales: Looking back, looking forward. Fungal Biology 121(4), 307-321.

Swofford DL. 2003 - PAUP*: Phylogenetic Analysis Using Parsimony, * and Other Methods, Version 4.0b10, Sinauer Associates, Sunderland.

Tamura K, Stecher G, Peterson D, Filipski A, Kumar S. 2013 - MEGA6: molecular evolutionary genetics analysis version 6.0. Molecular biology and evolution 30(12), 2725-2729.

Vilgalys R, Hester M. 1990 - Rapid genetic identification and mapping of enzymatically amplified ribosomal DNA from several Cryptococcus species. Journal of Bacteriology 172(8), 42384246. 
Voglmayr H, Castlebury LA, Jaklitsch WM. 2017 - Juglanconis gen. nov. on Juglandaceae, and the new family Juglanconidaceae (Diaporthales). Persoonia 38, 136-155.

White TJ, Bruns T, Lee S, Taylor J. 1990 - Amplification and direct sequencing of fungal ribosomal RNA genes for phylogenetics. PCR protocols: a guide to methods and applications $18,315-322$.

Wijayawardene NN, Hyde KD, Rajeshkumar KC, Hawksworth DL et al. 2017 - Notes for genera: Ascomycota. Fungal Diversity 86(1), 1-594.

Wyka SA, Broders KD. 2016 - The new family Septorioideaceae, within the Botryosphaeriales and Septorioides strobi as a new species associated with needle defoliation of Pinus strobus in the United States. Fungal Biology 120(8), 1030-1040.

Yang T, Groenewald JZ, Cheewangkoon R, Jami F et al. 2017 - Families, genera, and species of Botryosphaeriales. Fungal Biology 121(4), 322-346. 